\title{
O Direito ao EsqueCimento Frente aOS Mecanismos de MEMÓRIa ETERNA
}

\author{
Carlos Henrique Pazzinatto* \\ Cinthia Obladen de Almendra Freitas*
}

Introdução.1 Breve Evolução da Era da Informação. 2 Os Mecanismos de Memória Eterna. 2.1. Backup. 2.2 Cache. 2.3 Consequências dos Mecanismos de Memória Eterna. 3 Identidade na Internet e suas Fragilidades. 4 Direito ao Esquecimento. Considerações Finais. Referências.

\section{RESUMO}

$\mathrm{O}$ artigo aborda o direito ao esquecimento e à vida privada frente às diversas ferramentas existentes na Internet que não apenas produzem uma cópia de segurança, ou memória para acesso rápido, mas armazenam os dados deixando-os eternamente à disposição dos usuários. Apresenta-se breve histórico em relação à evolução dos meios de comunicação, assim como o advento da era da informação. São discutidos os efeitos positivos e negativos dessas ferramentas, assim como do uso da Internet, combinação que fortalece a memória eterna de dados e fatos. Estabelece-se uma relação entre três elementos: evolução da tecnologia, personalidade e direito ao esquecimento. Finalmente, conclui-se que os sites de cache, se bem utilizados, são essenciais para pesquisas acadêmicas e aos poucos criam algo similar a um museu permanente de história da Internet. Por outro lado, o meio eletrônico necessita de mecanismos de controle contra abusos cometidos e, consequentemente, entende-se pela responsabilização na esfera Cível e Penal, para justamente coibir e prevenir condutas que possam prejudicar pessoas, entidades, empresas e governos.

Palavras-chave: Direito ao esquecimento. Personalidade. Privacidade. Memória Cache e Cópias de Segurança.

* Mestrando em Direito pelo Programa de Pós-Graduação em Direito da PUCPR, Especialista em Direito e Processo Tributário Empresarial (PUCPR) e Bacharel em Direito (PUCPR). Atualmente é Técnico Judiciário do Tribunal de Justiça do Paraná. E-mail: carlos@tipr.jus.br

** Doutora em Informática pela Pontifícia Universidade Católica do Paraná (PUCPR). Professora Titular da Pontifícia Universidade Católica do Paraná (PUCPR) para o curso de Direito (Módulos Temáticos: Perícias e Laudos Técnicos; Crimes e Fraudes por Computador). Professora Permanente do Programa de Pós-Graduação em Direito (PPGD) da PUCPR. Pesquisadora do Grupo de Pesquisa "Direito do Consumo e Sociedade Tecnológica" (PUCPR/CNPq). E-mail: cinthia@ppgia.pucpr.br 


\section{INTRODUÇÃO}

No início das civilizações, as formas de comunicação eram primitivas e artesanais, porém, desde sempre envolveram e desenvolveram tecnologia. Gritos, sinais de fumaça, objetos deixados no meio da trilha, assim como as marcações no interior de cavernas faziam parte da comunicação primitiva. Com o advento do telégrafo, assim como da eletricidade, tornou-se possível estender as comunicações entre os homens para distâncias mais longas, em tempo reduzido. $\mathrm{O}$ rádio desempenhou papel primordial, juntamente com a mídia impressa, para que as pessoas recebessem notícias sobre o que estava acontecendo, local ou globalmente, por meio da tecnologia de ondas de rádio AM.

Recentemente, na década de 1950, com a televisão, foi possível ver as imagens de objetos e pessoas (a quais, na época do rádio, apenas podiam ser imaginados) se movimentando, falando, no inicio em preto e branco, e depois por meio de imagens coloridas e até mesmo em transmissões realizadas ao vivo.

Após um tempo, com o aperfeiçoamento e integração das tecnologias, assim como com o desenvolvimento dos semicondutores e microprocessadores, foi possível iniciar a utilização dos computadores para uso pessoal e como ferramenta no dia-a-dia, seja para realizar uma tarefa, seja para entretenimento.

Ainda na década de 90, quando a rede mundial de computadores estava engatinhando, de comunicação por meio de $\mathrm{BBS}^{1}$ já impressionava a todos frente à possibilidade de transmissão de arquivos, dados, entre outros. Na sequência, aperfeiçoando-se as tecnologias já existentes, a World Wide Web, tornou-se acessível aos domicílios, por meio da Internet discada, a qual tinha sua velocidade limitada, assim como a tarifação cobrada em horas de acesso.

Por fim, sanadas eventuais limitações iniciais, permitiu-se a comunicação com velocidade visivelmente superior às iniciais, mais adequada às necessidades humanas atuais, assim como uma disponibilidade de acesso mais abrangente.

Nesse quadro, a Internet tornou possível, por meio de seus bancos de dados e sistemas de indexação e busca de informações, acessar dados, fatos, acontecimentos, notícias, vídeos, imagens, ou seja, uma infinidade de arquivos de dados sobre temas variados, transpondo fronteiras pela comunicação direta em tempo real, possibilitando velocidade de acesso à informação e desenvolvimento das áreas de conhecimento humano. Vive-se o paradigma everyware preconizado por Greenfield ${ }^{2}$, a saber:

Ainda mais invasivo, mas difícil de perceber, é que o computador saiu da mesa de trabalho e se insinua em nossa vida diária. Essa tecnologia da informação ubíqua - 'everyware' - aparecerá em muitos contextos diferentes e tomará uma variedade de formas, mas afetará quase todos nós, estejamos ou não conscientes disto.

Não há mais que se falar somente em hardware e software, muito menos em estruturas do tipo fixo, por exemplo, telefone fixo ou computador desktop 
que significa literalmente "em cima da mesa", ou seja, fixo a um único local e utilizando infraestrutura de fios, cabos e tomadas elétricas.

A computação sem computadores, tal qual prevista por Weiser ${ }^{3}$, trabalha não somente com o conceito de estar em qualquer lugar, mas sim em qualquer coisa. Entenda-se "coisa" como sendo qualquer aparato ou equipamento que possa realizar processamento de informações, sejam estes aparentemente eletrônicos ou não.

Deve-se ter em mente também que o paradigma everyware é relativo ${ }^{4}$, ou seja, cada resultado ou resposta obtida num determinado momento depende não somente das ações e atitudes passadas, mas também de um grande número arbitrário de outras entradas (inputs) a partir de pontos distantes e conectados não necessariamente de modo direto (peer-to-peer) por interesse mútuo. Na verdade, o grau de pervasividade e entrelaçamento com o dia-a-dia das pessoas fará com que cada um reavalie seus relacionamentos com outras pessoas e consigo mesmo ${ }^{5}$.

Todavia, essa facilidade de comunicação proporcionada pelas Tecnologias de Informação e Comunicação (TIC), especialmente pela Internet, causou um efeito indesejado e relacionado com a possibilidade do acesso a qualquer informação a partir de qualquer lugar e a partir de qualquer dispositivo eletrônico, ou seja, o efeito indesejado repercute nos direitos à intimidade da pessoa humana. Imagens e vídeos de fatos que ocorreram há muito tempo ou que não deveriam mais estar disponíveis para todos, podem causar prejuízos à imagem da pessoa e até mesmo ser tratados como crime. Questiona-se: será que a sociedade moderna necessita armazenar tudo sobre todos o tempo todo? O direito ao esquecimento surge justamente quando se torna cada vez mais difícil definir fronteiras entre direitos fundamentais em rota de colisão, tais como, de um lado, o direito à informação e à não censura; e de outro, o direito à intimidade, à vida privada e à imagem, entre outros.

Em verdade, o problema de extrapolar a interpretação do que é direito à informação em contraponto ao direito à intimidade, vem desde a era do rádio, com grau pouco maior na era televisiva e infinitamente mais abrangente na era digital. $\mathrm{O}$ direito ao esquecimento busca resguardar os direitos inerentes à personalidade humana, como a intimidade da pessoa, o direito à imagem, sendo que esta não pode ser violada por momentos e situações que não fazem mais parte do presente, para todos que desejarem ter acesso, em qualquer momento, visto que essa exposição pode causar prejuízos, os quais devem ser reparados na esfera judicial.

Coube, portanto, ao estudo entender a relação entre o direito ao esquecimento e os mecanismos de memória eterna, disponíveis na Internet, como por exemplo, o backup e os mecanismos de cache, que passam despercebidos, e permitem arquivamento de dados e informações em estruturas de memória secundária em modo ad eternum nos sistemas digitais. A discussão refere-se a quando e como tais mecanismos de memória eterna podem ser considerados uma violação ao direito à intimidade da pessoa humana. 
A partir dessas considerações, o presente artigo tem o escopo de apresentar a perspectiva do direito ao esquecimento frente à era digital na sua consequente possibilidade de registro e disponibilização permanente, por meio de mecanismos de memória eterna, de uma infinidade de acontecimentos no universo digital. $\mathrm{O}$ artigo é resultado de projeto de pesquisa e segue método dedutivo para relacionar os mecanismos de memória eterna ao direito de esquecimento, tendo como fundamentação teórica a dignidade da pessoa humana. A pesquisa tem caráter explicativo, passando pelas fases da pesquisa exploratória e descritiva.

Finalmente, o artigo permite avaliar os mecanismos de memória eterna, lembrando que se bem utilizados, são essenciais para pesquisas acadêmicas, e aos poucos criam algo similar a um museu permanente de história da Internet. Por outro lado, o meio eletrônico necessita de mecanismos de controle contra abusos cometidos e, consequentemente, entende-se pela responsabilização na esfera Cível e Penal, para justamente coibir e prevenir condutas que possam prejudicar pessoas, entidades, empresas e governos. A linha dorsal do artigo encontra-se organizada sobre os problemas decorrentes do funcionamento de tais mecanismos a ponto de alavancar danos morais e materiais, sendo o foco as pessoas que veêm suas vidas expostas, muitas vezes incapazes de se recuperar socialmente, sem possibilidade de defesa.

\section{BREVE EVOLUÇÃO DA ERA DA INFORMAÇÃO}

Após a era da revolução industrial, surge a era da informação, também conhecida como a era digital, que teve como base as invenções do microprocessador, a rede de computadores, a fibra óptica e o computador pessoal. Essa era revolucionou a comunicação por meio dos sistemas rápidos, eficientes, capazes de fazer chegar, a inúmeras pessoas ao mesmo tempo, um volume nunca antes possível de informações em qualquer parte do globo terrestre. Conforme menciona Dourado ${ }^{6}$ :

[...] a Terra tem-se tornado cada vez menor graças à interligação, à facilidade de comunicação entre os povos, surgida a partir da criação da rede mundial de computadores, que, se por um lado aproxima culturas e nações tão diferentes, num intercambio instantâneo, por outro faz um raio X dos abismos existentes entre estas nações.

A era da informação permitiu a expansão do acesso aos livros, documentos, comunicação com pessoas, visualização de notícias em tempo real, entretenimento diversificado, e uma quantidade de conhecimentos singulares, dos mais necessários aos mais fúteis.

A grande integração digital teve forte aceleração com o advento da Word Wide Web, a rede mundial de computadores, que, interligados, permitem a transferência de dados em qualquer parte do mundo. Esclarecendo a terminologia de algumas expressões tecnológicas, nas palavras de Andrighi: 
Nesse contexto, merecem destaque os provedores de serviços de internet; aqueles que fornecem serviços ligados ao funcionamento dessa rede mundial de computadores, ou por meio dela. Trata-se de gênero do qual são espécies as demais categorias, como: (i) provedores de backbone (espinha dorsal), que detêm estrutura de rede capaz de processar grandes volumes de informação. São os responsáveis pela conectividade da internet, oferecendo sua infraestrutura a terceiros, que repassam aos usuários finais acesso à rede; (ii) provedores de acesso, que adquirem a infraestrutura dos provedores backbone e revendem aos usuários finais, possibilitando a estes conexão com a internet; (iii) provedores de hospedagem, que armazenam dados de terceiros, conferindo-lhes acesso remoto; (iv) provedores de informação, que produzem as informações divulgadas na internet; e (v) provedores de conteúdo, que disponibilizam na rede os dados criados ou desenvolvidos pelos provedores de informação ou pelos próprios usuários da web.

[...] Na hipótese específica dos sites de busca, verifica-se a disponibilização de ferramentas para que o usuário realize pesquisas acerca de qualquer assunto ou conteúdo existente na web, mediante fornecimento de critérios ligados ao resultado desejado, obtendo os respectivos links das páginas em que a informação pode ser localizada.

Essa provedoria de pesquisa constitui uma espécie do gênero provedor de conteúdo, pois esses sites não incluem, hospedam, organizam ou de qualquer outra forma gerenciam as páginas virtuais indicadas nos resultados disponibilizados, se limitando a indicar links em que podem ser encontrados os termos ou expressões de busca fornecidos pelo próprio usuário.

[...] $\bigcirc$ mecanismo de busca dos provedores de pesquisa trabalha em 3 etapas: (i) uma espécie de robô navega pela web identificando páginas; (ii) uma vez identificada, a página passa por uma indexação, que cataloga e mapeia cada palavra existente, compondo a base de dados para as pesquisas; e (iii) realizada uma busca pelo usuário, um processador compara os critérios da pesquisa com as informações indexadas e inseridas na base de dados do provedor, determinando quais páginas são relevantes e apresentando o resultado.

A Internet facilita a coleta de informações, ampliando o universo do conhecimento, produzindo alterações na cultura contemporânea, economia, política e, tem caráter revolucionário nas relações sociais. É possível inclusive, traçar um paralelo entre essas interconexões, e a visão holística de Harding ${ }^{8}$, a respeito do homem e sua relação com o meio em que vive, no caso, com outros da mesma espécie, sendo as relações catalisadas pela Internet.

A forma como as pessoas interagem mudou, sendo o contato humano muitas vezes substituído pelo virtual, principalmente pela interação nas redes sociais, como Facebook, Instagram, Twitter, aplicativos de smartphone como Whatsapp, entre outros. 
Com tudo isso, o acesso a informações pessoais, seja de alguém conhecido ou de um cidadão comum, tornou-se muito fácil, permitindo a violação da vida privada e da intimidade, seja por meio de disponibilização de informações, dados, vídeos ou até mesmo disponibilização de partes de processos judiciais pela Internet.

A insegurança acerca da utilização de novas tecnologias e as fragilidades da Internet remetem à sociedade de risco, trazida por Ulrich Beck. Para o autor, a humanidade tem enfrentado o risco da autodestruição pelas decisões que toma9 . Assim, a sociedade de risco residual se converteu em uma sociedade não segura, com riscos cada vez maiores e indeterminados.

Por outro lado, o ser humano vive naturalmente em rede, a própria vida em sociedade insere as pessoas por meio das relações que desenvolvem durante a vida, primeiro na família, depois na escola, na vizinhança, no trabalho, entre outros.

A configuração em rede é peculiar ao ser humano, ele se agrupa com seus semelhantes e vai estabelecendo relações de trabalho, de amizade, enfim, relações de interesses que se desenvolvem e se modificam conforme a sua trajetória. Assim, o indivíduo vai delineando e expandindo sua rede conforme sua inserção na realidade social.

As redes sociais sempre existiram de diversas formas, e de acordo com Marteleto ${ }^{10}$, representam "[...] um conjunto de participantes autônomos, unindo ideias e recursos em torno de valores e interesses compartilhados”. Equivocadamente, temos o Facebook, Twitter e outros, como redes sociais, porém, ao se observar o conceito, estas seriam na verdade mídias sociais, visto que a rede é a estrutura que sustenta os relacionamentos em si.

Assim, deve-se ter em mente a definição da área de Informática, na qual rede "é o meio físico, juntamente com software, que interliga dois ou mais computadores para transmissão de dados, voz, imagens, som ou vídeo e, ainda, para compartilhar recursos"11.

Enfim, as chamadas redes sociais na Internet não se limitam à comunicação e relacionamento, mas também são fonte de pesquisa e notícias, todavia, com maior interatividade e participação dos integrantes. É possível não apenas o acesso à informação, mas também sua geração, muito diferente do jornal, por exemplo, no qual a atitude do leitor é passiva e sem interatividade. Além do mais, recentemente as redes sociais foram descobertas como espaço de manifestações ${ }^{12}$.

Considerando-se o exposto, coube ao estudo entender os mecanismos de memória eterna, uma vez que tais mecanismos possibilitam a discussão do direito ao esquecimento frente às TICs. 


\section{OS MECANISMOS DE MEMÓRIA ETERNA}

Os mecanismos de memória eterna fazem parte da Internet e estão intimamente ligados à impossibilidade de excluir em definitivo um conteúdo que em algum momento esteve disponível na rede mundial de computadores. Portanto, segue-se com a apresentação dos seguintes mecanismos: backup e cache; visando ao entendimento do modo como os dados são eternizados por meio da Internet.

\subsection{Backup}

O mecanismo de backup, de acordo com Meirelles ${ }^{13}$ consiste em "processo de duplicar dados armazenados" tendo por objetivo a utilização em caso de perda, alteração indevida ou modificação acidental ou intencional. Os mecanismos de backup são classificados como procedimentos de segurança, sendo que dispositivos de armazenamento podem ser previstos e alocados estrategicamente, considerando-se a estrutura de armazenamento de dados como um todo ou o local físico de armazenamento ${ }^{14}$. No caso de necessidade de restauração dos dados, os arquivos poderão ser configurados até a data e hora do último backup realizado.

De acordo com a Microsoft ${ }^{15}$, existem diferentes tipos de backup, a saber: normal dar espaço (executado quando se cria um conjunto de backup pela primeira vez), diário, diferencial (copia arquivos criados ou alterados desde o último backup normal ou incremental), incremental (cópia somente os arquivos criados ou alterados desde o último backup normal ou incremental) e o de cópia (realiza a cópia de todos os arquivos selecionados pelo usuário ou sistema), sejam estes online ou offline.

A periodicidade das copias varia com a importância e grau de carregamento do sistema. Ou seja, sistemas que realizam a entrada de grandes volumes de dados por hora ou dia, necessitam de cópias de segurança mais frequentes. De um modo geral, nos computadores de uso pessoal, o backup é realizado com menor frequência, sendo que em empresas ou no setor público, o backup pode ser realizado até mesmo várias vezes ao dia. Sobre a importância do backup, Stallings ${ }^{16}$ coloca:

Fazer backups regulares de dados em um sistema é outro controle crítico que auxilia na manutenção da integridade do sistema e dos dados de usuários. Há muitas razões pelas quais os dados podem ser perdidos por um sistema, incluindo falhas de hardware ou software, ou corrupção acidental ou deliberada. Também pode haver requisitos legais ou operacionais para a retenção de dados. Backup é o processo de fazer cópias de dados em intervalos regulares, permitindo a recuperação de dados perdidos ou corrompidos durante períodos de tempo relativamente curtos, de algumas horas a algumas semanas.

O backup difere do arquivamento vez que o objetivo deste é reter copias durante longo período de tempo, e não apenas a recuperação do sistema. Nesse sentido, ainda de acordo com Stallings ${ }^{17}$, tem-se que: 
Arquivamento é o processo e reter cópias de dados durante longos períodos de tempo, da ordem de meses ou anos, para cumprir requisitos legais e operacionais de acesso a dados passados. Esses processos são frequentemente interligados e gerenciados em conjunto, embora abordem necessidades distintas.

Cabe destacar, tal qual Meirelles ${ }^{18}$, que não somente a integridade física do sistema e dos dados é importante, mas também a integridade lógica dos dados, isto significa que se deve questionar se "os dados armazenados são confiáveis, representam a realidade dos fatos”. Conforme Bowen et al a segurança da informação na Internet tem três conceitos básicos, a saber: confidencialidade, integridade e disponibilidade. Os autores apresentam tais conceitos como sendo:

Confidentiality: Preserving authorized restrictions on information access and disclosure, including means for protecting personal privacy and proprietary information.

Integrity: Guarding against improper information modification or destruction, and includes ensuring information non-repudiation and authenticity.

Availability: Ensuring timely and reliable access to and use of information. ${ }^{19}$

Entende-se, portanto, que por meio da confidencialidade toda a informação deve ser protegida de acordo com o grau de sigilo de seu conteúdo, visando à limitação do seu acesso e uso apenas às pessoas para quem as informações são destinadas. A integridade, por sua vez, garante que toda informação deve ser mantida na mesma condição em que foi disponibilizada pelo seu proprietário, visando a protegê-las contra alterações indevidas, intencionais ou acidentais. E, por último, a disponibilidade assegura que toda informação gerada ou adquirida por um indivíduo ou instituição deve estar disponível aos seus usuários no momento em que os usuários necessitem das informações para qualquer finalidade.

A utilização de técnica da virtualização permite que sistemas hospedados em um servidor físico sejam transferidos para outros servidores, por exemplo, em uma estrutura de nuvem computacional (cloudcomputing), executando o balanceamento de cópias de segurança dos sistemas. Esta abordagem possibilita que a restauração de cópias de segurança (backup) seja concluída em uma pequena fração de tempo, quando comparada ao tempo que levaria se realizada com base em servidores físicos tradicionais ${ }^{20}$.

Tem-se, portanto, que o backup é mecanismo essencial à vitalidade e manutenção dos sistemas computacionais. Porém, o uso para que os dados sejam eternizados e disponibilizados por meio da Internet pode causar prejuízos às pessoas, entidades, empresas e governos tal qual é apresentado e discutido no presente artigo. 


\subsection{Cache}

A palavra cache, em inglês, conforme o dicionário Oxford ${ }^{21}$ tem como significado "um local escondido ou inacessível para armazenar objetos valiosos, mantimentos ou munição" 22 ou mesmo "a coleção de um mesmo tipo de objeto escondido nesse lugar" 23 .

$\mathrm{Na}$ área de Informática, existe o conceito de memória cache, que é um dos tipos de memória com acesso extremamente rápido utilizada para armazenar os dados mais frequentemente acessados pelo processador, evitando que ele tenha que buscar informações na memória RAM (Random Access Memory ou Memória de Acesso Randômico), que comparativamente tem menor velocidade, limitando o desempenho do sistema à velocidade desta. Dodonov ${ }^{24}$ define cache como "uma técnica que possibilita armazenar os dados mais relevantes na memória, reduzindo a necessidade de acessar os dispositivos de armazenamento e aumentando o desempenho das operações de leitura e escrita de dados”.

Segundo Macarthy ${ }^{25}$ a memória cache "possui uma fração da memória principal", sendo implementada "em tecnologias com velocidades de acesso semelhantes à do processador".

Há também a memória cache associada ao Browser, o qual é um programa (software) para auxiliar a navegação entre as páginas web na Internet, sendo utilizado para armazenar, seja no computador ou no smartphone, o caminho (path) quando o usuário acessa uma página de um website qualquer. Cabe ao browser a comunicação entre o dispositivo e os servidores, de modo a processar os dados recebidos pelo usuário a partir dos servidores da Internet e também processar as respostas no caso de buscas ou acesso a dados e informações.

Funciona como um arquivo temporário em que o acesso é local (no próprio dispositivo, por exemplo, no celular), permitindo acesso com maior velocidade, evitando a perda de tempo carregando novamente os mesmos arquivos.

Assim, para o ambiente Web, a memória cache é como uma cópia de uma página web, com utilização especifica. Conforme Santos ${ }^{26}$, a utilização do cache em ambiente Web, permite a disponibilização dos "serviços dentro de níveis aceitáveis de tempo de resposta, pois grande parte do tráfego é, muitas vezes, formado pela passagem de diversas cópias dos mesmos objetos de informação".

O cache na Web é implementado por meio de mecanismos como "programas robôs" que realizam o rastreamento e efetivam backups instantâneos de cada página dos sites consultados para que, em caso de eventual indisponibilidade do site buscado, seja possível acessá-lo. Assim, ao acessar o cache, é possível estar diante de uma versão desatualizada ou excluída da página.

Importante ressaltar que o tipo de cache tratado neste artigo se refere a este último, devido às diversas páginas armazenadas por sites específicos. 
Como exemplo deste mecanismo, em um site de acesso público, que por razões técnicas esteja fora do ar, ainda assim será possível ter acesso ao conteúdo anteriormente disponível, praticamente, na íntegra, por meio da pesquisa em mecanismos de busca que possuam cache, utilizando essa opção, exibindo versão não muito distante da data atual.

Além do Google, esse mesmo tipo de cache é gravado também em outros sites, como o Cachedpages.com ${ }^{27}$ e o "Internet Archive Waybackmachine $e^{28 ", ~ e s t e ~ u ́ l t i m o ~}$ com mais de 427 bilhões de páginas gravadas, desde a sua criação em 1996, além de permitir a visualização de diversas versões das mesmas páginas conforme as datas em que foram gravadas. Esses mecanismos, conforme Pazzinatto ${ }^{29}$, " [...] demonstra de maneira clara que quando se envia um arquivo para a rede mundial de computadores, o risco dele ser apagado e perdido é mínimo se comparado ao que na verdade acontece, sua 'eternização'”.

Deste modo, foram analisados dois mecanismos (backup e cache) que possibilitam a manutenção de dados e informações de maneira eterna na Internet. Cabe, portanto, avaliar as consequências dos mecanismos de memória eterna.

\subsection{Consequências dos Mecanismos de Memória Eterna}

Considerando-se os mecanismos de backup e de cache, tem-se estabelecidas formas de duplicação e manutenção dos arquivos na rede mundial de computadores, sendo que se devem considerar ainda as seguintes consequências: o efeito cascata e a associação das novas ferramentas com a identidade (pessoal ou institucional).

O efeito em cascata consiste no uso combinado dos mecanismos, por exemplo, backup do cachê. Além disto, deve-se considerar que qualquer usuário pode realizar o download de conteúdos disponibilizados na Internet, desde uma simples cópia de uma página web em seu computador, seja de um site disponível, seja de uma página web disponível em algum mecanismo de cache.

Desta forma, tem-se que o efeito cascata poderá acontecer de diferentes formas e maneiras a depender dos interesses dos usuários, do nível de conhecimento técnico do usuário e, ainda, dos aplicativos e softwares utilizados.

Outro ponto relevante é a associação das novas ferramentas com a identidade. Isto pode ocorrer por meio da integração entre os mecanismos de memória eterna com os mecanismos de busca. Os mecanismos de busca não são descritos e tratados detalhadamente neste artigo, mas podem ser sucintamente entendidos como sendo os programas (software) que permitem a busca por argumentos de pesquisa, seja este uma ou um conjunto de palavras, imagens ou faces (rostos).

Antes de termos, por exemplo, o mecanismo de busca Google, que se utiliza de bots(robôs) para aperfeiçoar as pesquisas, era necessário cadastrar as páginas e os sites nos mecanismos então existentes, como o Cadê, Infoseek, Yahoo, entre 
outros. Desta forma, ficava estabelecido o vínculo entre o endereço URL(Uniform Resource Locator) da página, nome do destino, entre outros.

As buscas eram realizadas em velocidade muito menor e de forma muito menos abrangente. Hoje, ao se pesquisar o nome de uma pessoa qualquer, tem-se uma infinidade de resultados, apontando dados pessoais, profissionais, imagens, vídeos, entre outros; muitas vezes sem se ter conhecimento que tais conteúdos estavam disponibilizados, inclusive de fatos muito pretéritos. No Google Earth, por exemplo, também se pode ter acesso às imagens de satélite antigas, de um endereço específico, ou para aquele momento de nostalgia em relação à cidade em que se vive.

E para agravar a situação, poderão ser oriundas de cache de conteúdo que desconhecíamos, e que ainda estarão lá, em total dissonância com qualquer possibilidade de esquecimento.

Diante do que foi apresentado, encontra-se a fragilidade da Internet e do sistema informático como um todo, devido à impossibilidade de que uma pessoa, possa facultativamente, ou mesmo que por meios judiciais, excluir algo da rede, seja do sistema de busca, de sites de relacionamento, blogs e até mesmo dos aplicativos que permitem a troca de mensagens instantâneas. Esta ação tem pouco efeito na atual era digital, pois ao se colocar algo que seja veiculado pela Internet, o conteúdo pode ter ser duplicado, remetido para outra área de armazenamento, enviado para outro computador, entre outras ações, ou seja, o conteúdo nunca se perde.

Assim, a facilidade de veiculação de conteúdo está justamente criando um novo problema, ou seja, a eternização das informações e o não respeito ao direito de esquecimento, tornando-se um obstáculo instransponível, visto que, em verdade, mesmo que se tenha a prerrogativa geral da possibilidade de tirar o conteúdo indesejado da Internet, este ficará disponível em algum mecanismo de memória, podendo ser acessado novamente a qualquer momento, copiado, disponibilizado e assim por diante.

Neste contexto de evolução das tecnologias de informação e comunicação, foram estudados os mecanismos de memória eterna como elemento central da discussão do direito ao esquecimento, visto que tais mecanismos proporcionam a perpetuação de dados e informações pessoais no mundo digital, exacerbando a fragilidade da identidade da pessoa humana.

\section{IDENTIDADE NA INTERNET E SUAS FRAGILIDADES}

É razoável supor que muitos indivíduos podem ter o seu comportamento alterado quando da utilização de uma máquina que lhes permita a ele ter a sensação de poder ou extensão dos seus sentidos. Um motorista, quando está ao volante, na qualidade de condutor, não possui o mesmo comportamento quando deixa seu veículo e anda na calçada em meio as pessoas como pedestre. 
Analogamente, pode-se definir a mesma situação em relação aos usuários de Internet. Atrás do monitor do computador (celular ou tablet), em meio às várias janelas abertas, seja no browser, seja em aplicativos, a sensação de estar camuflado num outro 'ambiente', num outro mundo, pode levar a algumas alterações no seu comportamento habitual.

O fato de se estar por trás do monitor pode gerar uma sensação de afrouxamento das coerções morais típico do anonimato, podendo assim o usuário moldar uma identidade conforme sua personalidade real ou imaginada. Isso não se dá apenas de modo viciado na origem, mas a própria utilização das redes sociais exige dos usuários a criação de um perfil, o qual favorece a construção de uma projeção da identidade desejada pelo usuário.

Acontecimentos passados ou identidades pessoais criadas de modo equivocado, diante dos mecanismos de memória eterna, culminam por criar um desconforto permanente que conduz à 'imperdoabilidade' e 'eternização' de cada ato, seja ele equivocado ou pensado.

Essa 'eternização' dos acontecimentos passados e da identidade pessoal criada no mundo digital não leva em consideração a evolução da personalidade com o tempo. É como se cada usuário ainda fosse avaliado pelos atos que praticou quando era criança. De modo análogo, os atos praticados por um adulto de 18 anos não seriam os mesmos de uma pessoa com mais tempo de vida, por exemplo, aos 40 ou 50 anos. Antes a informação e conteúdo se perdiam com o tempo, hoje, a Internet e os mecanismos de busca associados aos mecanismos de memória eterna favorecem a 'eternização' e, por vezes, surge esse desconforto.

Existem pessoas que sabem lidar e viver muito bem com tais situações. A própria relativização do princípio da privacidade para os 'nascidos' na era digital dá conta de que esse desconforto poderia ser ignorado.

Prensky ${ }^{30}$ traz à discussão importante reflexão ao constatar que: "Nossos alunos têm mudado radicalmente. Os alunos de hoje não são mais as pessoas para as quais o sistema educacional foi concebido para ensinar" ${ }^{31}$. O autor explica que não foram somente as roupas e as gírias que se modificaram nas últimas décadas do século XX, mas que ocorreu um evento, uma singularidade tão representativa, que não se pode mais voltar atrás. $\mathrm{O}$ autor aponta que tal singularidade caracterizou-se pela chegada e rápida disseminação das tecnologias digitais. Para ele, a geração que está na faculdade nos dias atuais é a $1^{\text {a }}$ geração nascida e criada neste novo contexto, ou seja, os nascidos na década de 80 , quando se iniciava o domínio das tecnologias digitais, podem assim ser considerados. Por isso, Prensky ${ }^{32}$ escolheu o termo "Nativos Digitais" para designar esta geração de estudantes.

Portanto, as pessoas nascidas depois de 1990 podem ser consideradas como sendo os "nascidos na sociedade tecnológica". E os demais, o que são? Prensky"33 denomina-os como sendo "Imigrantes Digitais", aqueles que não nasceram no mundo digital, mas que buscam se adaptar e adotar muitos aspectos das novas tecnologias como parte de suas vidas. 
De acordo com Paesani ${ }^{34}$ :

O desenvolvimento da informática colocou em crise o conceito de privacidade, e, a partir dos anos 80 , passamos a ter um novo conceito de privacidade que corresponde ao direito que toda pessoa tem de dispor com exclusividade sobre as próprias informações mesmo quando disponíveis em banco de dados.

Todavia, as pessoas não são iguais e os acontecimentos durante a vida possuem pesos e valores diferentes para cada pessoa, cada família, conforme cultura, educação, religião. Imagine, por exemplo, um acontecimento na vida de uma criança, levado para a Internet por meio das redes sociais. Anos após, o simples fato desse acontecimento ter sido carregado ou postado, permitiu que diversas cópias fossem feitas, seja pelo site por meio de mecanismos de memória (cache ou backup), seja pelos próprios usuários, amigos ou não da criança.

É difícil lidar com essa relativização da privacidade, mesmo para os 'imigrantes digitais' que não desejam navegar na rede. Tem-se, por exemplo, a questão de fotos em família ou na casa de amigos. Pode ser que uma das pessoas não tenha vontade de ter qualquer imagem sua divulgada na Internet, inclusive sequer utilize redes sociais, mas pelo fato da imagem ter sido capturada por alguém do grupo, que utiliza as redes sociais, este alguém pode postar ou carregar o arquivo na rede. Eis o conflito entre exposição e eternização. A imagem estará ali, para sempre. Na Internet não há ainda 'prescrição' ou 'validade' dos arquivos. Pelo contrário, é como se fosse um livro da verdade, que tinha páginas faltando, mas que os próprios mecanismos e algoritmos dão cabo de preencher suas lacunas, reproduzindo a qualquer momento aquilo que estava outrora esquecido.

Neste sentido, Arenhart ${ }^{35}$ aponta que:

As inovações tecnológicas, sem sombra de dúvida, implicam a mutação completa da noção de vida privada, bem como de sua lesão. A diminuição de fronteiras que elas acarretam permite um contato mais próximo das pessoas e a violação mais frequente da esfera intima do ser humano. Em nome do direito à informação, a pessoa é devassada em sua vida particular e revirada do avesso, na busca pela melhor notícia, ou por aquela de maior impacto.

Surge, então, a necessidade de o Direito se preocupar com estas situações, no afã de preservar o mínimo da esfera de privacidade da pessoa humana, impedindo sua confusão com o ente social.

Além do mais, é comum a criação e utilização de perfis falsos na Internet, inclusive nas redes sociais. Por outro lado, ainda existem aqueles que utilizam login e senha de outros usuários para permanecer no anonimato, não importando qual seja o objetivo final.

Neste contexto, embora se tenha a possibilidade de rastreamento por meio do endereço de IP (Internet Protocol), e até mesmo identificação do hardware que realizou o acesso, o fato de se estar por detrás de um aparato tecnológico (com- 
putador ou celular), muitas vezes não se tem a possibilidade de se saber ao certo a identidade da pessoa que está realizando o acesso ou a postagem de conteúdo.

Recentes estudos demonstram que a aplicação de técnicas de mineração de dados possibilita a definição do perfil do usuário à medida que ele utiliza a Internet e as redes sociais ${ }^{36}$. Tal qual discutido por Freitas ${ }^{37}$, estas ferramentas podem ser utilizadas com a finalidade de direcionar anúncios de produtos e serviços de acordo com o perfil dos usuários-consumidores. Para tanto, palavras, frases e expressões contidas em e-mails ou em textos postados nas redes sociais podem ser processadas por meio de algoritmos inteligentes.

Por outro lado, a facilidade de acesso da Internet modificou completamente o comportamento das pessoas, muitas vezes causando doenças e transtornos. É comum em todas as faixas etárias, como crianças na tenra idade, que ainda não aprenderam a falar ou nem mesmo tenham coordenação motora desenvolvida, estarem com os dedinhos nos tablets ou nos smartphones com tela touchscreen, utilizando jogos interativos, criados especificamente para o público infantil.

Os "Nativos Digitais", no Brasil, de acordo com o Centro de Estudos sobre as Tecnologias da Informação e da Comunicação ${ }^{38}$, apontam que o uso do computador pelas crianças representa $57 \%$, sendo superior ao uso feito pelos adultos (53\%). O presente artigo traz à discussão os dois extremos em termos de faixas etárias, ou seja, crianças (5 a 9 anos) e idosos (60 anos ou mais).

De acordo, também, com o referido levantamento ${ }^{39}$, observou-se que apenas 29\% das crianças de 5 a 9 anos já utilizaram a Internet, sendo que o lugar a partir do qual realizam o acesso é a casa (49\%), tendo o acesso na escola alcançado $27 \%$. Sobre o uso de celulares, a pesquisa apontou que $65 \%$ das crianças têm acesso a esse tipo de equipamento, mesmo sem possuírem seu próprio aparelho celular.

Interessante destacar que este mesmo relatório apresenta as habilidades relacionadas com o uso do computador para crianças entre 5 e 9 anos de idade, sendo que $99 \%$ já utilizou o mouse, $80 \%$ fez desenhos no computador, $64 \%$ usou o computador para escrever, $60 \%$ escutou música no computador, $24 \%$ fez contas no computador e $8 \%$ utilizou o microfone para falar com outra pessoa.

Neste mesmo sentido, adolescentes e adultos estão casa vez mais sintonizados com esse universo digital ${ }^{40}$, principalmente por meio dos relacionamentos virtuais nas redes sociais, esquecendo-se muitas vezes de ter uma vida no "mundo real" e criando como consequência quadros psicológicos de dependência da Internet, não importando o dispositivo utilizado para acesso ${ }^{41}$.

Freitas $^{42}$ questiona a exposição pública na Internet que faz crescer a vulnerabilidade, tanto do usuário, quanto do consumidor, afirmando que "O indivíduo é o mesmo, mas a atuação é distinta e complexa, visto que quanto maior a exposição, maior é a vulnerabilidade e, portanto, como esperar que este usuário-consumidor se porte de maneira consciente diante do que revela de si 
próprio?". Bello ${ }^{43}$ mostra, a partir de pesquisa da empresa F-Secure, que " $86 \%$ dos brasileiros dizem se expor demais nas redes sociais". E, de acordo com estudo realizado por Ruiz e Río ${ }^{44}$, "88,1\% dos jovens na Espanha publicam dados pessoais reais em seus perfis nas redes sociais".

Sibilia ${ }^{45}$ explica que "Todas essas tendências de exposição da intimidade que proliferam hoje em dia, portanto, vão ao encontro e prometem satisfazer uma vontade geral do público: a avidez de bisbilhotar e "consumir" vidas alheias". Dal Bello ${ }^{46}$ relata que

[...] em 1 de outubro, por ocasião do lançamento do Google Street View no Brasil, perguntei a um jovem (aqui nomeado Jr., 19 anos) se ele não ficava "assustado" com tamanha exposição. Afinal, lá estava a sua rua, a sua casa, o seu portão. Ele respondeu que não, afinal, "minha geração cresceu com a Internet. A gente não está muito preocupado com essa tal privacidade. Pra gente, isso é normal". Ficou patente que o termo marcava um diferencial entre nós: seu descaso pela problemática estava em consonância com o orgulho por pertencer a uma nova geração.

Assim, a fragilidade que acompanha a Internet afeta os seus usuários de modo direto à medida em que estes se expõem por meio de textos, imagens ou vídeos. Eis o confronto entre identidade no mundo digital e exposição. Desta forma, a criação ou utilização de uma ou mais identidades na Internet, verdadeiras ou não, faz crescer a fragilidade da estrutura de rede como um todo, uma vez que o presente está diretamente ligado ao passado. $\mathrm{O}$ foco do presente artigo diz respeito a este passado, seja desta identidade pessoal estabelecida na Internet, seja em relação à vida "real" cotidiana em que imagens, histórias e vídeos podem ser rapidamente recuperados de algum ponto escondido da rede mundial de computadores. Sabe-se com o embasamento apresentado que o armazenamento de tudo sobre todos o tempo todo, na sociedade moderna, faz aumentar a fragilidade da pessoa humana.

\section{DIREITO AO ESQUECIMENTO}

É impressionante a capacidade de armazenamento de informações na rede mundial de computadores. A gama infinita de dados disponibilizados em ambiente digital pode ter armazenado alguns acontecimentos passados que causam vergonha ou arrependimento na pessoa que não queria ter conteúdo sobre si exposto em público. Tudo isto a apenas um clique de distância. Considerando-se o exposto, cabe abordar a questão jurídica da vida privada, intimidade, imagem e direito ao esquecimento.

Esclarece Caldas ${ }^{47}$ que, frequentemente, confundem-se conceitos relativos à honra, imagem e vida privada, bens jurídicos parcelares do direito de personalidade, apontando que:

Não raro essas três espécies de direitos de personalidade são confundidas, principalmente no momento de sua efetiva tutela. 
É comum que, frente a um ato concreto de violação de qualquer desses direitos, haja dúvida se a lesão está atingindo a honra ou a imagem, ou, ainda, a vida privada, quando não ocorre a violação simultânea de todos ou de dois deles.

O direito à intimidade é muito importante e com o advento da Internet vem sofrendo com um jogo de metamorfose que, de um lado, preconiza a sua relativização, e por outro lado, tem aumentada a relevância. Segundo Dourado ${ }^{48}$ :

O direito à intimidade é tema de relevantíssimo interesse nos dias atuais devido a um confronto eminente entre a essência do homem e as consequências do progresso material que o violenta, rompe mesmo com o que existe de mais puro e intimo em cada um de nós e transforma em assunto de conhecimento público, exterminando com a privacidade.

Fato é que a informação 'viaja' por meio da Internet com uma facilidade que não se pode controlar. Questiona-se: como impedir que uma informação falsa ou mesmo maliciosa sobre uma pessoa qualquer, divulgada na Internet, possa ser retirada completamente da rede? Ou ainda, quais procedimentos devem ser aplicados para que a situação seja esclarecida e comprovada a fraude? E, como reparar o dano se a informação já foi divulgada para várias pessoas, replicada e espalhada?

$\mathrm{Na}$ atual fase da era digital, a procura por reparação de danos morais e materiais causados pela divulgação de vídeos, fotos, textos e toda diversidade de informação referente a alguém, vem crescendo exponencialmente, sendo que vários casos já foram julgados em tribunais no Brasil e no mundo. $\mathrm{O}$ direito à imagem é problema jurídico complexo, e de acordo com Fernandes ${ }^{49}$ "não se exaure no direito à intimidade, irradiando-se, antes, a outras províncias".

O direito à imagem está assegurado no art. $5^{\circ}$, inciso X, da Constituição da República Federativa do Brasil ${ }^{50}$, que assegura não só a inviolabilidade à honra e imagem como, também, prevê o direito de indenização face à sua violação.

No mesmo sentido, o Superior Tribunal de Justiça editou a súmula 403, na qual diz o seguinte: "Independe de prova do prejuízo a indenização pela publicação não autorizada da imagem de pessoa com fins econômicos ou comerciais" ${ }^{51}$.

$\mathrm{Na}$ definição de Costa Junior ${ }^{52}$ direito de imagem é "o direito de impedir que terceiros venham a conhecer-lhe a imagem, pouco importando [...] o modo pelo qual vem executado o retrato da pessoa. Fotografia, pintura, escultura".

O direito de imagem não está limitado apenas à proteção do direito fundamental da pessoa humana, mas sim apresenta relação, também, com o direito à propriedade intelectual sobre determinadas realizações, sobretudo quando há interesse econômico envolvido.

Na mesma esteira, Durval ${ }^{53}$ leciona sobre o direito de imagem: "é a projeção da personalidade física do indivíduo no mundo exterior. Portanto, seria considerado um Direito Natural, equiparável ao da própria vida [...]”. 
Conforme Fachin ${ }^{54}$, o direito à imagem se desdobra em três níveis evolutivos, assim, primeiramente, não se admitindo a existência do direito de imagem (teoria negativista). Na segunda fase, reconhecendo a existência, mas como reflexo de outro instituto jurídico e, finalmente, num terceiro momento, o direito de imagem é reconhecido como direito autônomo, desvinculado de qualquer instituto jurídico.

A privacidade, por sua vez, conforme Rodotà 55 , pode ser definida como "o direito de manter o controle sobre as próprias informações”. Qualquer pessoa tem o direito de querer que algum fato, imagem, ou acontecimento de sua vida particular seja esquecido pela opinião pública, mesmo que autorizada, à época dos fatos, a sua divulgação.

As pessoas mudam com o tempo e não é justo que algo que as incomoda, seja este assunto subjetivo ou objetivo, permaneça 'ativo', pois a pessoa não pode sofrer punição da coletividade, principalmente a repressão moral, sobre algo que lhe ocorreu há muitos anos ou que simplesmente, não deveria ter sido exposto ao público.

Pergunta-se: haveria então a possibilidade de alguém apagar (deletar) algum conteúdo considerado impróprio ou até mesmo vexatório à sua imagem, por considerar que tal disponibilidade de informação excede na sua divulgação ao público?

O direito ao esquecimento não é recente, entretanto, tomou dimensões extraordinárias com a ampliação do uso da Internet. Em verdade, a preocupação com o que é divulgado em ambiente digital pode causar muitos transtornos para pessoas que estão completamente à mercê deste sistema extremamente rápido e eficiente para transmitir, replicar e disseminar a informação, seja ela verídica ou não. Conforme apresenta Costa Junior ${ }^{56}$, tem-se que

O homem, enquanto indivíduo que integra a coletividade, precisa aceitar as delimitações que lhe são impostas pelas exigências da vida em comum. E as delimitações de sua esfera privada deverão ser toleradas tanto pelas necessidades impostas pelo Estado, quanto pelas esferas pessoais dos demais concidadãos, que poderão perfeitamente conflitar ou penetrar por ela.

Tendo em vista a repercussão que os danos causados pela divulgação da informação na Internet vêm causando a milhares de pessoas, o direito ao esquecimento encontra refúgio no direito Europeu, ainda esbarrando em questões como os limites entre o que é de interesse público e o que é relativo à vida privada, nesse sentido Rodotà ${ }^{57}$ aponta que

A este último propósito, retorna o tema do "direito ao esquecimento", tão presente durante as discussões dos anos passados. Ora diante da difusão de regras sobre a obrigação de eliminar dados coletados, observou-se que dessa forma fica prejudicada a memória histórica da sociedade. Ainda um paradoxo. No momen- 
to em que cresce enormemente a quantidade de informação que pode ser coletada, estará a quantidade que pode ser conservada fadada a diminuir?

Até mesmo o direito ao esquecimento tem seu peso e sua medida. Fatos históricos, mesmo que tratando da vida pessoal de pessoas públicas, mas que tenham relevância na história da sociedade podem não ser atingidos pelo direito ao esquecimento. Cabe, portanto, avaliar a evolução da personalidade como característica humana ao longo do tempo e, também, frente ao contínuo desenvolvimento das tecnologias de informação e comunicação (TIC).

Relevante aspecto da personalidade humana é que esta muda com o tempo. Evidente que alguns interesses, atividades, paixões, hobbies, profissões e uma infinidade de assuntos relacionados mudam com o passar dos anos, tendo em vista que a pessoa sempre estará em desenvolvimento.

Freire $^{58}$ aponta, como características principais do ser humano, sua condição de ser inacabado e, ainda, sua capacidade de se reconhecer inacabado e transformar tal condição, por meio de processo educativo:

Na verdade, diferentemente dos outros animais, que são apenas inacabados, mas não são históricos, os homens se sabem inacabados. Têm a consciência de sua inconclusão. Aí se encontram as raízes da educação mesma, como manifestação exclusivamente humana. Isto é, na inconclusão dos homens e na consciência que dela têm.

Nesse sentido, alguns assuntos que não mais dizem respeito à pessoa ou que não se queira mais que seja divulgado, visto o processo de transformação do ser humano, podem ser então excluídos ou deletados, ou mesmo, modificados. Sendo uma aparente faculdade da pessoa, retirar seu conteúdo da Internet, pois algo que tenha inserido há dez anos atrás pode não ter mais interesse na atualidade, por ter perdido a relevância ou por poder eventualmente transmitir uma informação equivocada da pessoa. Enfim, motivos são vários para que algo seja excluído da Internet. Excluir conteúdo pessoal da Internet é uma faculdade de cada pessoa, mas não é o que se observa na atualidade.

Depois de disponibilizada na Internet, por exemplo, a foto tirada há quinze anos continua disponível em algum lugar da rede, assim como vídeo, recado, declaração, e-mail, comentário, curtida, opinião, entre outros. Isto ocorre porque há uma falsa certeza, que ao excluir ou 'tirar do ar', qualquer conteúdo que estava na Internet, este desaparecerá. Entretanto, isto é uma falácia da era digital.

Evidente a necessidade de resguardar momentos que pertencem ao passado e que não precisam ou não deveriam ser mais divulgados ou disponibilizados. Um exemplo é o caso do Alaska, ${ }^{59}$ nos Estados Unidos da América, cuja legislação obriga que réus de crimes sexuais e sequestradores de crianças, se registrem em cadastro próprio a cada ano, por 15 anos, e dependendo do caso, para o resto da vida. Paralelo a isso, sites como homefacts.com divulgam os fatos ocorridos, o 
endereço do condenado, a foto, um mapa com relações de escolas próximas. Ao se realizar uma busca pelo nome, por consequência, se obtém como resultado os sites que contêm este tipo de informação.

Conclui-se, portanto, que a retirada de conteúdo de um determinado site, seja por escolha própria ou determinação judicial, não é eficaz, visto que outros sites ou aplicativos, ou mesmo usuários da Internet, podem ter copiado e deixado arquivado tal conteúdo no seu computador de uso pessoal. A qualquer momento este conteúdo pode voltar a circular na rede mundial de computadores, enfraquecendo mecanismos de defesa ou até mesmo frustrando a aplicação das decisões do poder Judiciário (em que pese possam dificultar a divulgação e a transmissão de replicação de conteúdo) mesmo que se apliquem penalidades.

Por conseguinte, as angústias pessoais por ter divulgado determinado conteúdo, exposto na Internet, são em vão. Uma vez carregado, o conteúdo vai se "perder" na rede. Pode-se fazer uma analogia, explicando que o conteúdo irá navegar, não se tendo até o momento mecanismos eficientes para apagar ou deletar determinado conteúdo de modo definitivo. Mesmo que se queira deletar conteúdo publicado há décadas atrás, sempre existirá uma cópia em algum lugar, em algum computador, proporcionada e mantida pelos mecanismos de memória eterna. Pode-se, portanto, enunciar que é impossível retirar um conteúdo da Internet de modo definitivo, um dia este conteúdo reaparecerá.

\section{CONSIDERACุÕES FINAIS}

$\mathrm{O}$ artigo abordou o direito ao esquecimento e à vida privada frente às diversas ferramentas existentes na Internet que não apenas produzem uma cópia de segurança, ou memória para acesso rápido, mas armazenam os dados, deixando-os eternamente à disposição dos usuários. Apresenta-se breve histórico em relação à evolução dos meios de comunicação, assim como o advento da era da informação. Foram discutidos os efeitos positivos e negativos dessas ferramentas, assim como do uso da Internet, combinação que fortalece a memória eterna de dados e fatos. Estabelece-se uma relação entre três elementos: evolução da tecnologia, personalidade e direito ao esquecimento.

Entende-se que o direito ao esquecimento não deve ser relativizado, pelo contrário, deve ser melhor aplicado e normatizado. Considerando o caráter transfronteiriço da rede mundial de computadores, entende-se que há necessidade de regulamentação em nível global, principalmente no que tange ao direito de imagem das pessoas.

Os mecanismos de memória cache, em especial os sites de cache, têm realizado vasta captura de dados, deixando de se ater às questões de privacidade e direito ao esquecimento. Para conviver harmoniosamente com as novas tecnologias, poder-se-ia pensar em um modelo ideal no qual haveria um prazo em que os conteúdos expirassem, tal qual a validade de produtos, e caso fossem mantidos disponíveis, haveria a responsabilização dos sites. 
Por outro lado, é interessante haver um repositório de dados e informações, visando à busca com viés histórico, científico, social, ambiental e cultural, ou seja, em outras palavras, tal qual um museu cibernético, respeitando-se as restrições pessoais individuais, caso a caso. E, não como na atualidade, em que tudo é armazenado indiscriminadamente.

Deve-se ter em mente as vantagens do mecanismo de cache, que se bem utilizado, permite construir um repositório consistente voltado à pesquisa, inclusive para acesso aos conteúdos já disponibilizados em universidades e que não mais estão disponíveis.

Para tal, entende-se pela necessidade de regulamentação desses mecanismos, e paralelo a isso, o desenvolvimento de procedimentos computacionais (software) inseridos nas páginas da Internet, que forneçam uma validade ao conteúdo ou mesmo bloqueiem os mecanismos de cache, obrigando que se faça solicitações formais para a cópia e manutenção do conteúdo eventualmente disponibilizado.

Assim com o exposto pode-se verificar que mecanismos, aparentemente inofensivos, podem eventualmente trazer graves prejuízos à imagem, privacidade e intimidade das pessoas, acentuando a vulnerabilidade do usuário-consumidor-cidadão frente à Internet. Entende-se que a tecnologia pode ser utilizada para enfrentar os malefícios da tecnologia. Eis o confronto entre iguais.

Assegurar o direito à informação não significa desrespeitar o direito à intimidade, à vida privada, à honra e à imagem, assegurados pela mesma Constituição Federal de 1988. Quanto à proteção dos direitos da personalidade, a Internet não pode ser considerada um espaço anárquico onde não existem sanções para os violadores e tutela para aqueles que não possuam o domínio acerca de sua utilização. Essa afirmação, importante como princípio, revela-se pouco eficaz na prática.

Conclui-se que os sites de cache, se bem utilizados, são essenciais para pesquisas acadêmicas e aos poucos criam algo similar a um museu permanente de história da Internet. Por outro lado, o meio eletrônico necessita de mecanismos de controle contra abusos cometidos e, consequentemente, entende-se pela responsabilização na esfera Cível e Penal, para justamente coibir e prevenir condutas que possam prejudicar pessoas, entidades, empresas e governos.

\section{REFERÊNCIAS}

ANDRIGUI, Fátima Nancy. A responsabilidade civil dos provedores de pesquisa via internet. Rev. TST, Brasília, v. 73, n. 3, p. 65-66, jul./set. 2012.

ARENHART, Sérgio Cruz. A tutela inibitória da vida privada. São Paulo: Revista dos Tribunais, 2000. 
BECK, Ulrich. La Sociedad del Riesgo Global. España: Siglo Veintiuno, 2002. BOWEN, Pauline; HASH, Joan; WILSON, Mark. Information Security Handbook: A Guide for Managers. Recommendations of the National Institute of Standards and Technology, NIST Special Publication 800-100, oct., 2006.

BELLO, Bruno Iacona de. $86 \%$ dos brasileiros dizem se expor demais em redes sociais. Disponível em <http://www.superdownloads.com.br/materias/6392-86-brasileiros-dizem-se-expor-demais-redes-sociais.htm> Acesso em 15 out. 2015.

CALDAS, Pedro Frederico. Vida privada, liberdade de imprensa e dano moral. São Paulo: Saraiva, 1997.

CETIC.br - Centro de Estudos sobre as Tecnologias da Informação e da Comunicação. Pesquisa sobre o uso das tecnologias da informação e da comunicação no Brasil: 2005-2009. São Paulo: Comitê Gestor da Internet no Brasil, 2010.

COSTA JUNIOR, Paulo José da. O direito de estar só: tutela penal de intimidade. 2. ed. rev. e atual. São Paulo: Revista dos Tribunais, 1995.

DAL BELLO, Cíntia. Visibilidade, vigilância, identidade e indexação: a questão da privacidade nas redes sociais digitais. O Estatuto da Cibercultura no Brasil. LOGOS 34, v.34, n.1, p.139-151, 1 semestre, 2011.

DODONOV, Evgueni. Um mecanismo integrado de cache e prefetchting para sistemas de entrada e saída de alto desempenho. 2004. Dissertação (Mestrado)Universidade Federal de São Carlos, São Carlos: UFSCar, 1998.

DOURADO, Maria de Fatima Abreu Marques. Fundamentos do direito à intimidade. Porto Alegre: Sergio Antonio Fabris Ed., 2008.

DURVAL, Hermano. Direito à Imagem. São Paulo: Saraiva, 1988.

FACHIN, Zulmar Antônio. A Proteção Jurídica da Imagem. São Paulo: Celso Bastos Editor: Instituto Brasileiro de Direito Constitucional, 1999.

FERNANDES, Milton. Proteção civil da intimidade. São Paulo: Saraiva. 1977.

FONSECA, Franciele Fagundes; SENA, Ramony Kris R.; SANTOS, Rocky Lane A. dos; DIAS, Orlene Veloso; COSTA, Simone de Melo. The vulnerabilities in childhood and adolescence and the Brazilian public policy intervention. Revista Paulista de Pediatria [online], v. 31, n.2, p. 258-264, 2013.

FREIRE, Paulo Reglus Neves. Pedagogia do Oprimido. Rio de Janeiro: Paz e Terra, 2005.

FREITAS, Cinthia Obladen de Almendra. A vulnerabilidade do consumidor e a exposição pública na internet. In: III Encontro de Internacionalização do CONPEDI/Madrid, Universidad Complutense de Madrid (UCM); Facultad de Derecho. Florianópolis: CONPEDI, 2015. 
GREENFIELD, Adam. Everyware: the dawning age of ubiquitous computing. AIGA, New Riders, 2006.

HARDING, Stephan. In: MOLINA, Mário (Trad.). Terra-Viva: ciência, intuição e evolução de Gaia. São Paulo: Cultrix, 2008.

LAUDON, Kenneth C.; LAUDON, Jane P. Sistemas de Informação. Rio de Janeiro: Livros Técnicos e Científicos S.A., 1999.

MACARTHY, Marcello da Rocha; REIS, Ricardo A. L. Síntese de uma memória cache. 1998. Dissertação (Mestrado) - Universidade Federal do Rio Grande do Sul, Porto Alegre: UFRS, 1998.

MARCON JR, Arlindo; LAUREANO, Marcos; SANTIN, Altair Olivo; MAZIERO, Carlos Alberto. Aspectos de Segurança e Privacidade em Ambientes de Computação em Nuvem. Anais de Minicursos do SBSeg 2010. X Simpósio Brasileiro em Segurança da Informação e de Sistemas Computacionais, Porto ALEGRE, RS: SBC, p. 53-102, 2010. Disponível em: <http://professor.ufabc.edu. br/ joao.kleinschmidt/aulas/seg2011/nuvem.pdf>. Acesso em: 15 out. 2015.

MARTELETO, Regina Maria Análise de redes sociais: aplicação nos estudos de transferência da informação. Ciência da Informação, Brasília, v. 30, n. 1, p. 71/81, jan./abr., 2001.

MICROSOFT. Tipos de backup. Technet. 2015. Disponível em: $<$ https://technet. microsoft.com/pt-br/library/cc784306(v=ws.10).aspx>. Acesso em: 15 out. 2015.

MOBILON, Thiago. O potencial do WhatsApp para o uso em mineração de dados. Tecnoblog, 2014. Disponível em <https://tecnoblog.net/151635/potencial-whatsapp-mineracao-de-dados/>. Acesso em: 15 out. 2015.

OXFORD DICTIONARIES. Cache. Oxford Dictionaries. Disponível em <http://www.oxforddictionaries.com/pt/definição/inglês/cache>. Acesso em:15 out. 2015.

PAESANI, Liliana Minardi. Direito e Internet: liberdade de informação, privacidade e responsabilidade civil. 5. ed. São Paulo: Atlas, 2012.

PAMPLONA, Danielle Anne; FREITAS, Cinthia Obladen de Almendra. Exercício Democrático: a tecnologia e o surgimento de um novo sujeito. Pensar (UNIFOR), v. 20, p. 82-105, 2015.

PAZZINATTO, Carlos Henrique. Sociedade tecnológica e de consumo: agilidade versus segurança, contrato e internet, novo regime de proteção jurídica da internet. In: Direito do consumidor II [Recurso eletrônico on-line] organização CONPEDI/UFPB; coordenadores: Sérgio Urguhart de Cademartori, Leonardo Macedo Poli. Florianópolis: CONPEDI, 2014. p. 381-396. Disponível em<http:// www.publicadireito.com.br/publicacao/ufpb/livro.php?gt=248>. Acesso em: 15 out. 2015. 
PRENSKY, Marc. Digital Natives, Digital Immigrants. On the Horizon, MCB University Press, v. 9, n. 5, p. 1-6, 2001.

RODOTÀ, Stefano. In: MORAES, Maria Celina Bodin de (Org.) A vida na sociedade da vigilância. A privacidade hoje. Rio de Janeiro: Renovar, 2008.

RUIZ, Eva Espinar; RÍO, María José González. Jóvenes en las redes sociales virtuales. Un análisis exploratorio de las diferencias de género. Feminismo/s 14, p. 87-106, diciembre 2009.

SANTOS, Rogério Guaraci dos; CALSAVARA, Alcides. Substituição de objetos em cache na WWW baseado na semântica da informação. 2001. Dissertação (Mestrado) - Pontifícia Universidade Católica do Paraná, 2002.

SIBILIA, Paula. Os diários íntimos na internet e a crise da interioridade psicológica. Antroposmoderno. Disponível em: <http://antroposmoderno.com/ antro-version-imprimir.php?id_articulo=1143> Acesso em: 15 out. 2015.

STALLINGS, William; BROWN, Lawrie. In: MARQUES, Arlete Simille (Trad.). Segurança de Computadores: princípios e práticas. 2.ed. Rio de Janeiro: Elsevier, 2014.

TONO, Cineiva Campoli Paulino. Reflexão sobre o uso do computador e da internet acerca de aspectos teóricos e ergonômicos. In: ALMEIDA, Marcus Garcia; FREITAS, Maria do Carmo Duarte (Orgs.). A Escola no Século XXI, Volume 3: Virtualização das relações: um desafio da gestão escolar. Curitiba: Brasport, p. 33-59, 2013.

WEISER, Mark. Some computer science issues in ubiquitous computing. Communications of the ACM, July 1993. (reprinted as "Ubiquitous Computing". Nikkei Electronics; p. 137-143, December 6, 1993) Disponível em: <http://www.ubiq. com/hypertext/weiser/UbiCACM.html>. Acesso em: 15 out. 2

1 O BulletinBoard System (BBS) é um sistema informático, um software, que permite a conexão via telefone a um sistema por meio do seu computador e interagir com ele, com princípios similares à Internet.

2 Ever more pervasive, ever harder to perceive, computing has leapt off desktop and insinuated itself into everyday life. Such ubiquitous information technology - "everyware" - will appear in many different contexts and take a wide variety of forms, but it will affect almost every one of us, whether we're aware of it or not. (GREENFIELD, Adam. Everyware: the dawning age of ubiquitous computing. AIGA: New Riders, 2006, p. 9 , tradução nossa).

3 WEISER, Mark. Some computer science issues in ubiquitous computing. Communications of the ACM, July 1993. (reprinted as "Ubiquitous Computing". Nikkei Electronics; p. 137-143, December 6, 1993). Disponível em <http://www.ubiq.com/hypertext/weiser/UbiCACM.html> Acesso em: 15 out. 2015, p. 94.

4 Neste sentido GREENFIELD, op. cit., p. 81.

5 Ibidem, p. 84.

6 DOURADO, Maria de Fatima Abreu Marques. Fundamentos do direito à intimidade. Porto Alegre: Sergio Antonio Fabris, 2008, p. 36.

7 ANDRIGUI, Fátima Nancy. A responsabilidade civil dos provedores de pesquisa via internet. Rev. TST, Brasilia, v. 73, no 3, p. 65-66, jul/set 2012, p.65.

8 HARDING, Stephan. In: MOLINA, Mário (Trad). Terra-Viva: ciência, intuição e evolução de Gaia. São Paulo: Cultrix, 2008. 
9 BECK, Ulrich. La Sociedad del Riesgo Global. España: Siglo Veintiuno, 2002.

10 MARTELETO, Regina Maria Análise de redes sociais: aplicação nos estudos de transferência da informação. Ciência da Informação, Brasília, v. 30, n. 1, p. 71/81, jan./abr., 2001, p. 72.

11 LAUDON, Kenneth C. e LAUDON, Jane P. Sistemas de Informação. Rio de Janeiro: Livros Técnicos e Científicos S.A., 1999, p. 150.

12 PAMPLONA, Danielle Anne; FREITAS, Cinthia Obladen de Almendra. Exercício Democrático: a tecnologia e o surgimento de um novo sujeito. Pensar (UNIFOR), v. 20, p. 82-105, 2015.

13 MEIRELLES, Fernando de Souza. Informática: novas aplicações com microcomputadores. 2. ed., atual. e ampl. São Paulo: Makron Books, 1994, p. 589.

14 Ibidem, p. 467.

15 MICROSOFT. Tipos de backup. 2015. Technet. Disponivel em <https://technet.microsoft.com/pt-br/ library/cc784306(v=ws.10).aspx>. Acesso em: 15 out. 2015.

16 STALLINGS, William; BROWN, Lawrie. In: Marques, Arlete Simille (Trad.). Segurança de Computadores: princípios e práticas. 2.ed. Rio de Janeiro: Elsevier, 2014, p. 379.

17 Ibid., p. 380.

18 MEIRELLES, op. cit., p. 468.

19 BOWEN, Pauline; HASH, Joan; WILSON, Mark. Information Security Handbook: A Guide for Managers. Recommendations of the National Institute of Standards and Technology, NIST Special Publication 800-100, oct., 2006, p. 75.

20 MARCON JR, Arlindo; LAUREANO, Marcos; SANTIN, Altair Olivo; MAZIERO, Carlos Alberto. Aspectos de Segurança e Privacidade em Ambientes de Computação em Nuvem. Anais de Minicursos do SBSeg 2010 - X Simpósio Brasileiro em Segurança da Informação e de Sistemas Computacionais, Porto ALEGRE, RS: SBC, 2010, p. 53-102. Disponivel em: <http://professor.ufabc.edu.br/ joao.kleinschmidt/ aulas/seg2011/nuvem.pdf>. Acesso em: 15 out. 2015, p. 56.

21 OXFORD DICTIONARIES. Cache. Oxford Dictionaries. Disponivel em <http://www.oxforddictionaries. com/pt/definição/inglês/cache>. Acesso em:15 out. 2015.

22 A hidden or inaccessible storage place for valuables, provisions, or ammunition. (OXFORD DICTIONARIES, op. cit., tradução nossa)

23 A collection of items of the same type stored in a hidden or inaccessible place. (OXFORD DICTIONARIES, op. cit., tradução nossa)

24 DODONOV, Evgueni. Um mecanismo integrado de cache e prefetchting para sistemas de entrada e saída de alto desempenho. 2004. Dissertação (Mestrado) - Universidade Federal de São Carlos, São Carlos: UFSCar, 1998, p. 9.

25 MACARTHY, Marcello da Rocha; REIS, Ricardo A. L. Síntese de uma memória cache. 1998. Dissertação (Mestrado) - Universidade Federal do Rio Grande do Sul, Porto Alegre: UFRS, 1998, p. 31.

26 SANTOS, Rogério Guaraci dos; CALSAVARA, Alcides. Substituição de objetos em cache na WWW baseado na semântica da informação. 2001. Dissertação (Mestrado) - Pontifícia Universidade Católica do Paraná, 2002, p.1.

27 Cachedpaged é um banco de dados de impressão de tela ou uma versão de uma página web guardada em um momento específico e armazenada por um servidor web como uma cópia de backup.

28 WaybackMachine é um banco de dados digital criado pela organização Internet Archive, sem fins lucrativos, e que arquiva páginas da World Wide Web desde 1996.

29 PAZZINATTO, Carlos Henrique. Sociedade tecnológica e de consumo: agilidade versus segurança, contrato e internet, novo regime de proteção jurídica da internet. In: Direito do consumidor II [Recurso eletrônico on-line] organização CONPEDI/UFPB; coordenadores: Sérgio Urguhart de Cademartori, Leonardo Macedo Poli. Florianópolis: CONPEDI, 2014, p. 381-396. Disponível em <http://www.publicadireito.com. br/publicacao/ufpb/livro.php?gt=248> Acesso em: 15 out. 2015, p. 393.

30 PRENSKY, Marc. Digital Natives, Digital Immigrants. On the Horizon, MCB University Press, v. 9, n. 5, 2001, p. 1.

31 Our students have changed radically. Today's students are no longer the people our educational system was designed to teach. (PRENSKY, Marc, op. cit., p.1, tradução nossa)

32 PRENSKY, Marc, op. cit., p. 1.

33 Ibid., p. 2

34 PAESANI, Liliana Minardi. Direito e Internet: liberdade de informação, privacidade e responsabilidade civil. 5. ed. São Paulo: Atlas, 2012, p. 35. 
35 ARENHART, Sérgio Cruz. A tutela inibitória da vida privada. São Paulo: Revista dos Tribunais, 2000, p. 47.

36 MOBILON, Thiago. O potencial do WhatsApp para o uso em mineração de dados. Tecnoblog, 2014. Disponível em <https://tecnoblog.net/151635/potencial-whatsapp-mineracao-de-dados/> Acesso em: 15 out. 2015.

37 FREITAS, Cinthia Obladen de Almendra. A vulnerabilidade do consumidor e a exposição pública na internet. In: III Encontro de Internacionalização do CONPEDI/Madrid, Universidad Complutense de Madrid (UCM); Facultad de Derecho. Florianópolis: CONPEDI, 2015.

38 CETIC.br - Centro de Estudos sobre as Tecnologias da Informação e da Comunicação. Pesquisa sobre o uso das tecnologias da informação e da comunicação no Brasil:2005-2009. São Paulo: Comitê Gestor da Internet no Brasil, 2010, p. 26.

39 Ibidem, p. 28

40 FONSECA, Franciele Fagundes; SENA, Ramony Kris R.; SANTOS, Rocky Lane A. dos; DIAS, Orlene Veloso; COSTA, Simone de Melo. The vulnerabilities in childhood and adolescence and the Brazilian public policy intervention. Revista Paulista de Pediatria [online]., v.31, n.2, p. 258-264, 2013.

41 TONO, Cineiva Campoli Paulino. Reflexão sobre o uso do computador e da internet acerca de aspectos teóricos e ergonômicos. In: ALMEIDA, Marcus Garcia; FREITAS, Maria do Carmo Duarte (Orgs.). A Escola no Século XXI: Virtualização das relações: um desafio da gestão escolar. Curitiba-PR: Brasport, p. 33-59, 2013, v. 3.

42 FREITAS, Cinthia Obladen de Almendra, op. cit.

43 BELLO, Bruno Iacona de. $86 \%$ dos brasileiros dizem se expor demais em redes sociais. Disponível em: <http://www.superdownloads.com.br/materias/6392-86-brasileiros-dizem-se-expor-demais-redes-sociais. htm>. Acesso em: 15 out. 2015, p. 1.

44 RUIZ, Eva Espinar; RÍO, María José González. Jóvenes en las redes sociales virtuales. Un análisis exploratorio de las diferencias de género. Feminismo/s 14, p. 87-106, diciembre 2009, p. 97.

45 SIBILIA, Paula. Os diários íntimos na internet e a crise da interioridade psicológica. Antroposmoderno. Disponível em: 〈http://antroposmoderno.com/antro-version-imprimir.php?id_articulo=1143〉. Acesso em: 15 out. 2015, p. 5.

46 DAL BELLO, Cíntia. Visibilidade, vigilância, identidade e indexação: a questão da privacidade nas redes sociais digitais. O Estatuto da Cibercultura no Brasil. LOGOS 34, v.34, n.1, p.139-151, 1\% semestre, 2011, p. 149.

47 CALDAS, Pedro Frederico. Vida privada, liberdade de imprensa e dano moral. São Paulo: Saraiva, 1997, p.22.

48 DOURADO, op. cit.2008, p. 71.

49 FERNANDES, Milton. Proteção civil da intimidade. São Paulo: Saraiva. 1977, p.173.

50 BRASIL. Constituição da República Federativa do Brasil, 1988. Planalto.gov. Disponível em<http://www. planalto.gov.br/ccivil_03/Constituicao/Constituicao.htm>Acesso em: 15 out. 2015.

51 BRASIL. Superior Tribunal de Justiça - STJ. Súmula no 403, 2009. Disponível em <https://ww2.stj.jus. br/docs_internet/revista/eletronica/stj-revista-sumulas-2014_38_capSumula403.pdf $>$. Acesso em: 15 out. 2015.

52 COSTA JUNIOR, Paulo José da. O direito de estar só: tutela penal de intimidade. 2. ed. rev. e atual. São Paulo: Revista dos Tribunais, 1995, p. 54.

53 DURVAL, Hermano. Direito à Imagem. São Paulo: Saraiva, 1988, p. 105.

54 FACHIN, Zulmar Antônio. A Proteção Jurídica da Imagem. São Paulo: Celso Bastos Editor: Instituto Brasileiro de Direito Constitucional, 1999, p.61.

55 RODOTÀ, Stefano. In: MORAES, Maria Celina Bodin de (Org.). A vida na sociedade da vigilância. A privacidade hoje. Rio de Janeiro: Renovar, 2008, p. 92.

56 COSTA JUNIOR, op. cit., p.45.

57 RODOTÀ, op. cit., p.84.

58 FREIRE, Paulo Reglus Neves. Pedagogia do Oprimido. Rio de Janeiro: Paz e Terra, 2005, p. 83-84.

59 Alaska Department of Public Safety. Legis. Disponível em: <http://www.legis.state.ak.us/basis/folioproxy. asp?url=http://wwwjnu01.legis.state.ak.us/cgi-bin/folioisa.dll/stattx11/query=[group+section1263010!3A]/ doc/\{@1\}/hits_only>. Acesso em: 17 set. 2015. 


\title{
THE RIGHT TO BE FORGOTTEN AND THE MECHANISMS OF ETERNAL MEMORY
}

\begin{abstract}
This article broaches the right to be forgotten and the private life in face of the internet tools that not only back up files to be used as quick access memory, but also archive data, leaving them eternally available to users. A brief history of the evolution of the communication means, and the advent of the information age, as well, is presented. The positive and negative effects of these tools, and of the internet as a whole (a combination that strengthens eternal memory of data and facts) is displayed. A relationship among three elements: changes in technology, personality and the right to oblivion is established. Finally, it is stated that cache memory mechanisms, if well used, are essential for academic research, and gradually create something similar to a permanent museum of Internet history. On the other hand, electronic media requires control mechanisms against abuses, which consequently means responsibility under Civil and Criminal Law, just to restrain and prevent conducts that could harm people, organizations, businesses and governments.
\end{abstract}

Keywords: Right to be forgotten. Personality. Privacy. Cache Memory and Backup.

Submetido: 2 dez. 2015

Aprovado: 5 jan. 2016 